\title{
Follow-Up Study on the Effect of Cognitive Behaviour Therapy on Haemodialysis Adherence A randomised controlled trial
}

$$
\text { دراسة متابعة حول تأثير العلاج السلوكي المعرفي على الالتزام بالغسيل الكلوي }
$$

بليسي برابها فالساراج، شريباثي بهات، رافيندرا برابهو، آشا كاماث

ABSTRACT: Objectives: Patients with chronic kidney disease (CKD) undergoing haemodialysis often experience a myriad of psychosocial problems, resulting in poor adherence to their therapeutic regimen. This study aimed to examine the effect of cognitive behaviour therapy (CBT) on dialysis, fluid, drug and diet adherence among a previously reported sample of CKD patients undergoing haemodialysis. Methods: A randomised controlled trial was conducted between January 2013 to Febrary 2014 on a random selection of 67 CKD patients attending a tertiary multispecialty hospital in India. The experimental group $(n=33)$ was exposed to CBT, whereas the control group $(\mathrm{n}=34)$ received non-directive counselling. A haemodialysis adherence scale was developed and used to assess adherence to the treatment regimen. The effect size was calculated using Cohen's d statistics. Results: At six months, mean reductions from baseline were observed in the experimental group in terms of interdialytic weight gain $(-1.23 \mathrm{~kg}$; effect size: 0.57$)$, systolic blood pressure $(-22.18 \mathrm{mmHg}$; effect size: 0.71$)$ and diastolic blood pressure $(-10.06 \mathrm{mmHg}$; effect size: 0.72$)$, whereas mean increases were noted in haemoglobin $(+0.75 \mathrm{~g} / \mathrm{dL}$; effect size: 0.31$)$ and adherence to dialysis (+0.94; effect size: 0.51$)$, fluids (+16.34; effect size: 2.30$)$, diet (+61.19; effect size: $4.75)$ and drugs (+10.73; effect size: 1.3$)$. Differences from baseline were significantly higher in the experimental group compared to the control group $(P=0.001$ each). Conclusion: These results show that CBT is more effective than non-directive counselling for improving therapeutic adherence and physiological, clinical parameters among CKD patients undergoing haemodialysis.

Keywords: Chronic Kidney Disease; Hemodialysis; Patient Adherence; Cognitive Behavior Therapy; Hemoglobin; Weight Gain; Blood Pressure; Randomized Controlled Trial.

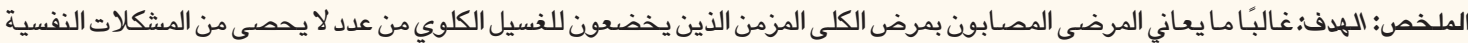

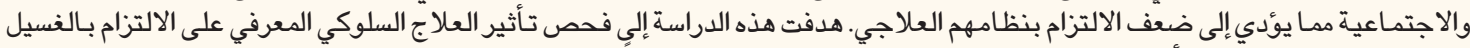

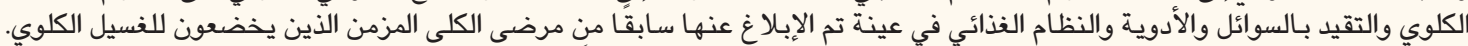

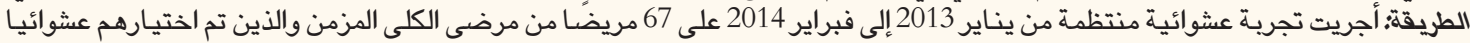

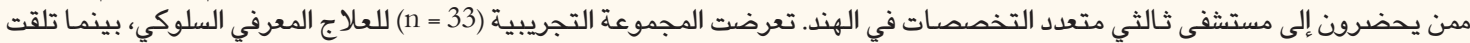

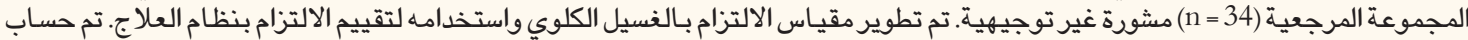

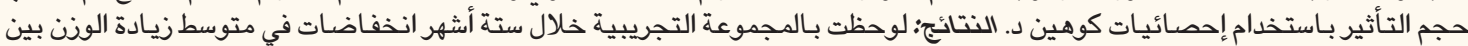

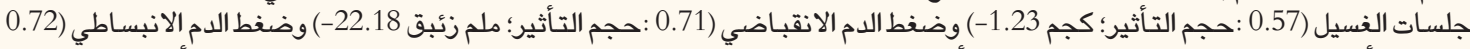

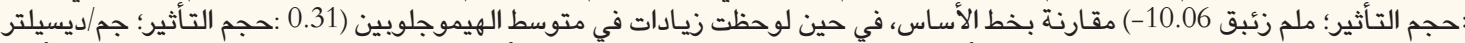

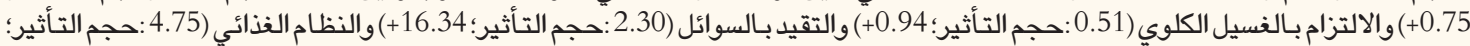

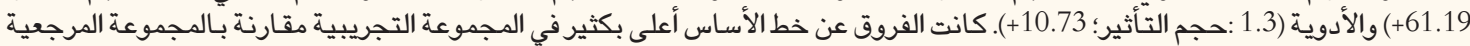

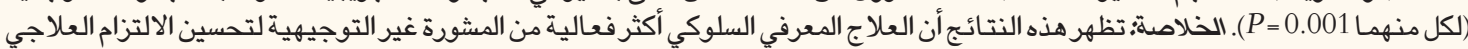

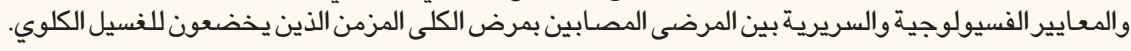

الكلمات المفتاحية؛ مرض الكلى المزمن؛ غسيل كلوي؛ التزام المريض؛ علاج سلوكي معرفي؛ هيموجلوبين؛ زيادة الوزن؛ ضغط الدم؛ تجربة عشوائية هنتظمة.

\section{AdVANCES IN KNOWLEDGE}

To the best of the author' knowledge, this is the first study in India to evaluate the effect of cognitive behaviour therapy (CBT) on patients with chronic kidney disease (CKD) undergoing haemodialysis using both objective physiological indicators along with subjective measures of therapeutic adherence.

\section{Application to Patient Care}

The results of this follow-up study support the inclusion of CBT in the routine management of CKD to improve treatment adherence. Such measures may increase the cost-effectiveness of care and decrease the burden of disease in this patient population. 
$\mathrm{C}$ HRONIC KIDNEY DISEASE (CKD) IS ONE OF the 20 most common disorders globally, with a prevalence rate of $11-13 \% .^{1}$ According to the Global Burden of Disease study, there was a $32 \%$ increase in renal failure-related deaths between 2005 and 2015. ${ }^{2}$ In kidney disease, the management of fluctuations in blood pressure, blood sugar and other parameters is challenging and there is a high risk of death due to heart disease and other causes. ${ }^{3}$ Ongoing haemodialysis is a critical and life-sustaining form of treatment for patients diagnosed with CKD, especially as kidney transplantation is not always feasible for legal, financial or medical reasons. ${ }^{4}$ As such, there has been a considerable rise in the usage of maintenance dialysis in recent years. ${ }^{5}$

However, patients often find it difficult to adhere to a regular regimen involving the strict administration and control of fluid, diet, medications and many hours of dialysis. ${ }^{6}$ McDade-Montez et al. reported that up to $18 \%$ of patients quit haemodialysis within four years due to depression. ${ }^{7}$ Other researchers have similarly found depressive symptoms to represent a significant early warning sign of poor outcomes and mortality among CKD patients. ${ }^{8,9}$ In India, adherence to dialysis is often low due to the lack of standard dialysis services in government hospitals and inadequate medical insurance to support treatment costs at private facilities. $^{5}$

End-stage renal disease represents a considerable drain on healthcare funding due to the enormous costs and prolonged nature of treatment, particularly among developing countries. ${ }^{10}$ Non-adherence to dialysis is associated with higher rates of morbidity and mortality ${ }^{11}$ Moreover, the aftermath of non-adherence in the context of chronic illnesses such as CKD often results in the wasting of valuable healthcare resources and poor health outcomes and quality of life. ${ }^{12}$ In turn, adherence to haemodialysis treatment and stable laboratory and physiological indicators are related to positive healthcare outcomes. ${ }^{13}$

Interventions involving cognitive or behavioural components have been shown to improve patient compliance ${ }^{8,14}$ Cognitive behaviour therapy (CBT) is a form of psychotherapy that aims to elicit, examine and replace negative thoughts to encourage emotional regulation and positive behavioural changes. ${ }^{15}$ This type of therapy is considered to be especially useful for patients with chronic diseases who face difficulties in following strict therapeutic regimens or to help alleviate common psychological conditions such as anxiety and depression. ${ }^{16-20}$ For example, dysfunctional thoughts such as 'nothing can improve my condition' can result in harmful emotions and practices such as missing dialysis sessions or skipping prescribed medicines, further reinforcing problematic beliefs. ${ }^{17}$

A previous randomised controlled trial was conducted to determine the effect of CBT on anxiety and depression among 67 patients undergoing haemodialysis. ${ }^{20}$ There was a significant reduction in mean anxiety $(\mathrm{F}=76.739 ; P=0.001)$ and depression (F $=57.326 ; P=0.001)$ scores in the experimental group compared to the control group. However, the initial study focused solely on improvements in anxiety and depression rather than patient adherence to treatment. ${ }^{20}$ Therefore, the current follow-up study's objective was to examine the efficacy of CBT intervention on therapeutic adherence among patients with CKD, including dialysis, fluid, diet, and drug adherence.

\section{Methods}

As previously reported, a randomised controlled trial was conducted between January 2013 to Febrary 2014 at the haemodialysis unit of a tertiary multispecialty hospital in India. ${ }^{20}$ The trial was conducted in accordance with the Consolidated Standards of Reporting Clinical Trials guidelines. ${ }^{21}$ The target population consisted of CKD patients aged 20 to 65 years undergoing maintenance dialysis for at least one year and who had scored $>7$ in any of the subscales of the Hospital Anxiety Depression Scale. ${ }^{20}$ Patients who could not read and write either English or the regional language of Kannada were excluded from the trial, as were patients who required ambulation assistance, those waiting for a kidney transplant and individuals who were being treated for a psychiatric illness.

In order to detect a difference of $25 \%$ and at a power of $80 \%$ and a $95 \%$ confidence level, the necessary sample size was calculated to be 33, accounting for a $20 \%$ attrition rate and based on an expected prevalence of general treatment adherence of $50 \%$. A total of 150 patients were screened for eligibility, of which 60 were excluded, 10 dropped out and 13 discontinued treatment, resulting in a final sample of 67 participants..$^{20}$ Computer-generated block randomisation was applied to assign patients to either group..$^{22} \mathrm{~A}$ total of 33 and 34 participants were thus allocated to the experimental and control groups, respectively.

Both groups were given routine care during dialysis; however, the experimental group received CBT, whereas the control group received nondirective counselling. The study was single-blinded by concealing the participants to the type of intervention 


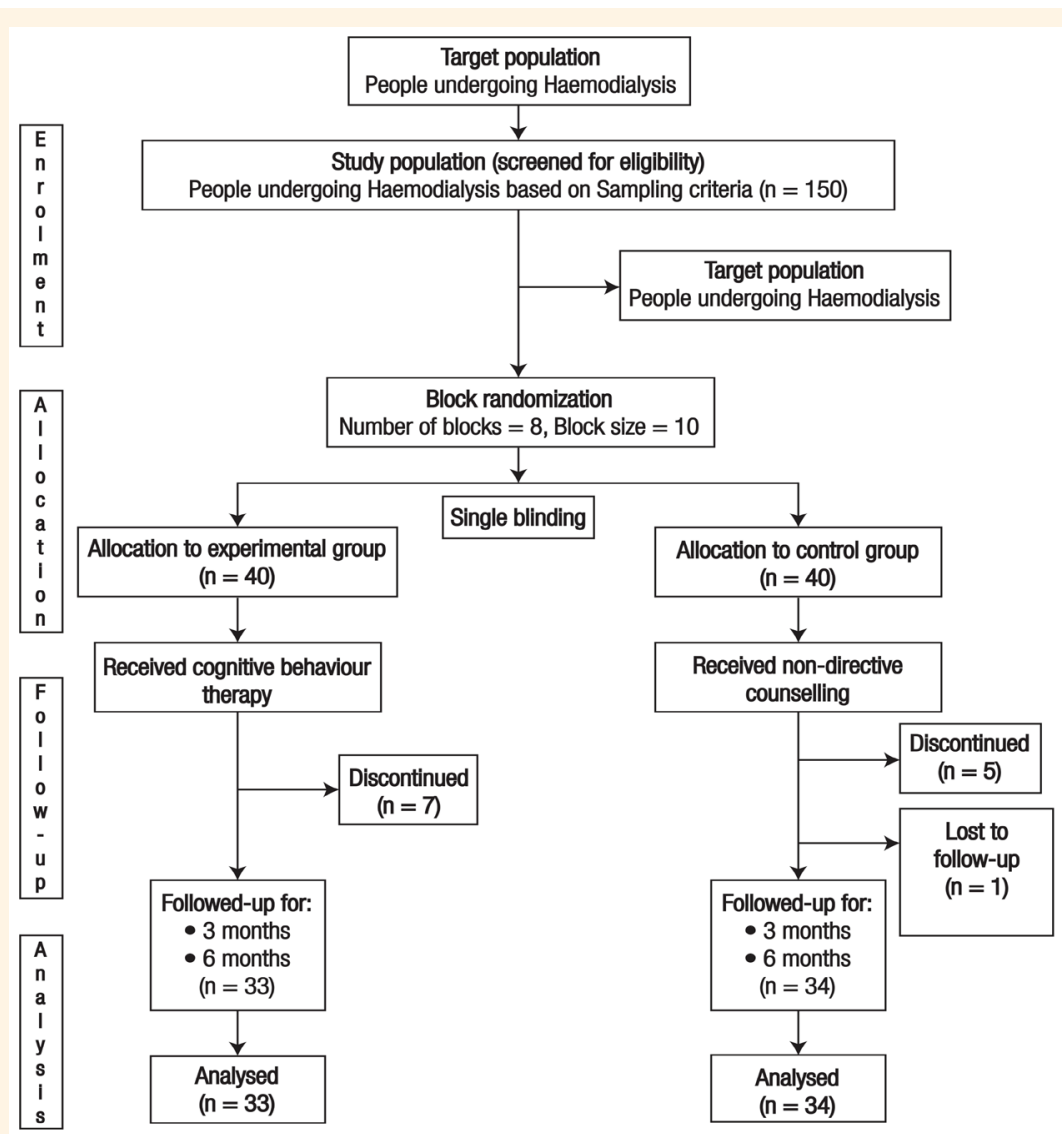

Figure 1: Flowchart showing the randomised controlled trial design utilised in the current study.

Reproduced with permission from Valsaraj BP, Bhat SM, Latha KS. Cognitive behaviour therapy for anxiety and depression among people undergoing haemodialysis: A randomised control trial. ${ }^{20}$

received. In addition, group allocation was kept confidential from dialysis staff and nephrologists as these individuals recorded information regarding certain adherence indicators, such as interdialytic weight gain (IDWG), blood pressure and haemoglobin. Full details of the study design have been previously published elsewhere [Figure 1]. ${ }^{20}$

According to group allocation, a specialist in psychiatric mental health nursing with prior CBT training administered either CBT or non-directive counselling to the patients. ${ }^{20}$ The therapist spent an equal amount of time with patients in both groups, with all participants receiving information concerning the importance of adherence. The CBT was administered over the course of 10 individual sessions conducted on a weekly basis, with each session lasting approximately 50 minutes to one hour. Cognitive, behavioural and didactic techniques were taught in order to alter maladaptive thoughts and non-adherent behaviours. ${ }^{20}$ A specific CBT module (including the objectives, techniques and roles of both the therapist and patient), diary (with daily homework for patients) and manual (reference material for the therapist on how to carry out the therapy) were developed. These documents were validated by nine experts in related fields, including clinical psychologists, psychiatric nurses, psychiatrists, nephrologists and dieticians.

Data were collected via patient records, laboratory testing and personal interviews with the patients and caregivers at three distinct points in time: (1) at baseline before the intervention; (2) at three months postintervention; and (3) at six months post-intervention. A haemodialysis adherence scale was developed specifically for the purposes of this study. Appropriate and relevant items were generated following an extensive literature review and discussion with experienced nephrologists, dialysis technicians, dieticians and dialysis patients and their caregivers.

The final version of the scale included five subscales: the adherence indicators, dialysis adherence, fluid adherence, diet adherence and drug adherence subscales. Items in the adherence indicators section consisted of data sourced directly from the patients' laboratory results and medical records, while information in the dialysis, fluid, diet and drug adherence subscales were collected during personal interviews with the participants, corroborated by interviews with the patient's caregiver (i.e. the parent, spouse or child regularly accompanying the patient to the hospital for the dialysis). 
Table 1: Baseline physiological indicators and adherence scores according to group allocation" among patients with chronic kidney disease undergoing haemodialysis at a tertiary multispecialty hospital in India $(\mathrm{N}=67)$

\begin{tabular}{|c|c|c|c|}
\hline \multirow[t]{2}{*}{ Indicator } & \multicolumn{2}{|c|}{ Mean \pm SD } & \multirow{2}{*}{$\begin{array}{c}\mathrm{F} \\
\text { value }\end{array}$} \\
\hline & $\begin{array}{l}\text { Experimental group } \\
(\mathbf{n}=33)\end{array}$ & $\begin{array}{l}\text { Control group } \\
(\mathbf{n}=34)\end{array}$ & \\
\hline IDWG in $\mathrm{kg}$ & $4.47 \pm 0.92$ & $4.39 \pm 0.78$ & 1.35 \\
\hline $\begin{array}{l}\text { Systolic BP } \\
\text { in } \mathrm{mmHg}\end{array}$ & $167.33 \pm 19.68$ & $163.59 \pm 18.53$ & 0.04 \\
\hline $\begin{array}{l}\text { Diastolic BP } \\
\text { in } \mathrm{mmHg}\end{array}$ & $98.24 \pm 9.52$ & $95.35 \pm 8.29$ & 0.15 \\
\hline $\mathrm{Hb}$ in $\mathrm{g} / \mathrm{dL}$ & $7.55 \pm 1.18$ & $7.62 \pm 1.09$ & 0.32 \\
\hline $\begin{array}{l}\text { Dialysis } \\
\text { adherence } \\
\text { score }\end{array}$ & $13.30 \pm 1.02$ & $13.38 \pm 0.95$ & 0.07 \\
\hline $\begin{array}{l}\text { Fluid } \\
\text { adherence } \\
\text { score }\end{array}$ & $34.27 \pm 2.88$ & $33.85 \pm 2.46$ & 0.30 \\
\hline $\begin{array}{l}\text { Diet } \\
\text { adherence } \\
\text { score }\end{array}$ & $138.45 \pm 5.85$ & $136.18 \pm 4.69$ & 0.14 \\
\hline $\begin{array}{l}\text { Drug } \\
\text { adherence } \\
\text { score }\end{array}$ & $22.39 \pm 4.09$ & $22.71 \pm 3.47$ & 2.59 \\
\hline
\end{tabular}

The adherence indicators subscale assessed physiological markers of adherence based on laboratory results and data from the patients' clinical records. Weight and blood pressure measurements were documented by the dialysis unit staff directly using calibrated electronic weighing machine and sphygmomanometers while haemoglobin was tested in the hospital laboratory. An average of two consecutive weight measurements were taken to indicate actual IDWG, as the gap between two dialysis sessions in a given week varied between two and three days. The dialysis adherence subscale consisted of five items assessing the frequency of skipping, shortening or delaying dialysis sessions, clarifying doubts with the healthcare team and the need for extra dialysis sessions (i.e. as an emergency measure in case of breathing difficulties due to fluid overload).

The fluid adherence subscale consisted of 15 items concerning fluid intake and fluid control behaviours. The diet adherence subscale consisted of 55 items assessing the consumption of various food categories (i.e. cereals, pulses, vegetables, fish, meat, fruits, nuts, snacks, sweets, pickles and oils) and cooking methods. ${ }^{23}$ The drug adherence subscale consisted of 11 items concerning the frequency of buying and taking prescribed medications or supplements (i.e. phosphorous binders or multivitamin and calcium supplements). Compliance

Table 2: Differences in physiological indicators and adherence scores over time according to group allocation* among patients with chronic kidney disease undergoing haemodialysis at a tertiary multispecialty hospital in India $(\mathrm{N}=67)$

\begin{tabular}{|c|c|c|c|c|c|c|}
\hline \multirow[t]{2}{*}{ Variable } & \multicolumn{2}{|c|}{ Mean \pm SD } & \multirow[t]{2}{*}{ df } & \multirow[t]{2}{*}{ F ratio } & \multirow[t]{2}{*}{$P$ value } & \multirow{2}{*}{$\begin{array}{c}\text { Effect } \\
\text { size }\end{array}$} \\
\hline & $\begin{array}{l}\text { Experimental group } \\
\qquad(\mathbf{n}=33)\end{array}$ & $\begin{array}{l}\text { Control group } \\
\quad(\mathbf{n}=34)\end{array}$ & & & & \\
\hline \multicolumn{7}{|l|}{ IDWG in kg } \\
\hline Baseline & $4.47 \pm 0.92$ & $4.39 \pm 0.78$ & & & & \\
\hline At 3 months & $3.18 \pm 0.77$ & $4.30 \pm 0.57$ & 2,130 & 60.41 & 0.001 & 0.57 \\
\hline At 6 months & $3.24 \pm 0.63$ & $4.69 \pm 0.47$ & & & & \\
\hline \multicolumn{7}{|c|}{ Systolic BP in mmHg } \\
\hline Baseline & $167.33 \pm 19.68$ & $163.59 \pm 18.53$ & & & & \\
\hline At 3 months & $144.85 \pm 13.49$ & $162.65 \pm 17.81$ & 2,130 & 76.66 & 0.001 & 0.71 \\
\hline At 6 months & $145.15 \pm 12.78$ & $165.59 \pm 17.09$ & & & & \\
\hline \multicolumn{7}{|c|}{ Diastolic BP in mmHg } \\
\hline Baseline & $98.24 \pm 9.52$ & $95.35 \pm 8.29$ & & & & \\
\hline At 3 months & $87.27 \pm 6.26$ & $94.12 \pm 7.83$ & 2,130 & 29.01 & 0.001 & 0.72 \\
\hline At 6 months & $88.18 \pm 6.35$ & $95.88 \pm 7.83$ & & & & \\
\hline \multicolumn{7}{|l|}{$\mathrm{Hb}$ in $\mathrm{g} / \mathrm{dL}$} \\
\hline Baseline & $7.55 \pm 1.18$ & $7.62 \pm 1.09$ & & & & \\
\hline At 3 months & $8.08 \pm 1.19$ & $7.52 \pm 1.12$ & 2,130 & 44.69 & 0.001 & 0.31 \\
\hline At 6 months & $8.30 \pm 1.23$ & $7.52 \pm 0.95$ & & & & \\
\hline
\end{tabular}

$S D=$ standard deviation; $d f=$ degrees of freedom; IDWG = interdialytic weight gain; $B P=$ blood pressure; Hb = haemoglobin. *The experimental group received cognitive behaviour therapy while the control group received non-directive counselling. 


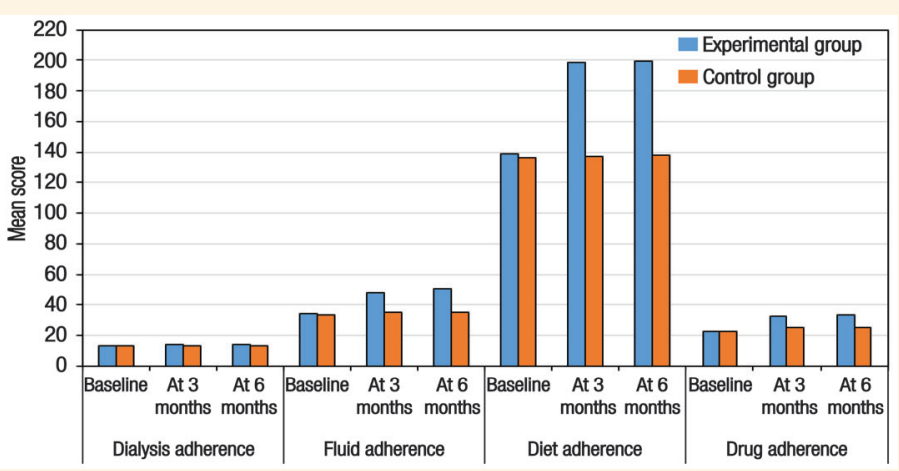

Figure 2: Chart showing mean adherence scores over time among patients with chronic kidney disease undergoing haemodialysis at a tertiary multispecialty hospital in India $(N=67)$. The experimental group $(n=33)$ received cognitive behaviour therapy while the control group $(n=34)$ received non-directive counselling.

with erythropoietin and antihypertensive medications was excluded from the latter subscale after a pilot study, since these agents were found not to be prescribed to all patients.

The scoring for each subscale was based on the responses to each of the items. In the dialysis and drug adherence subscales, most of the items were scored based on the frequency of the behaviour on a 3-point scale as either 1 for 'always', 2 for 'sometimes' or 3 for 'never'. In the fluid and diet subscales, scoring was based on the frequency of consumption of the drink or food item as either 1 for 'daily', 2 for 'once per week', 3 for 'once every 15 days', 4 for 'once per month' or 5 for 'never'. Reverse scoring was applied for positive behaviours; as such, a high score indicated high adherence. The scale was validated by nine experts from related disciplines and was pretested for feasibility on five patients. In addition, inter-rater and test-retest reliability was found to be acceptable ( $\mathrm{R}=$ 0.9 and 0.89 , respectively).

Data were analysed using the Statistical Package for the Social Sciences (SPSS), Version 22 (IBM Corp., Armonk, New York, USA). A repeated measure analysis of variance model was applied without adjusting for baseline variables to compare outcomes both within and between the two groups. Differences were calculated between mean variables or scores at baseline compared to those at six months for both groups. The effect size was calculated using Cohen's d statistics. A $P$ value of $<0.050$ was considered statistically significant.

Ethical approval for this study was obtained from the institutional ethics committee of Kasturba Hospital, Karnataka, India (ECR/146/Inst/KA/2013). Administrative permission to conduct the study was taken from the medical superintendent and the unit head of the dialysis unit. All participants provided informed consent after receiving information regarding the nature, duration and possible risks and benefits of the study including the right to withdraw at any point.

\section{Results}

This follow-up study included 67 previously reported patients with CKD undergoing maintenance dialysis. ${ }^{18}$ As described elsewhere, the majority of patients in the experimental and control groups were 43-65 years old (67\% and 66\%, respectively), male (70\% and $71 \%$, respectively), married (79\% and $79 \%$, respectively) and had started dialysis treatment one to three years prior to data collection (58\% and $56 \%$, respectively). ${ }^{20}$

The physiological indicators and adherence scores of the groups at baseline are shown in Table 1. At six months, there was a significant reduction in IDWG in the experimental group compared to the control group $(-1.23 \mathrm{~kg}$ versus $-0.3 \mathrm{~kg}$; effect size: $0.57 ; P=0.001)$. In addition, there was a significant difference in both systolic $(-22.18 \mathrm{mmHg}$ versus $+2 \mathrm{mmHg}$; effect size: $0.71 ; P=0.001)$ and diastolic $(-10.06 \mathrm{mmHg}$ versus $+0.53 \mathrm{mmHg}$; effect size: $0.72 ; P=0.001$ ) blood pressure at six months. There was also a significant increase in haemoglobin in the experimental group compared to the control group $(+0.75 \mathrm{~g} / \mathrm{dL}$ versus $-0.1 \mathrm{~g} / \mathrm{dL}$; effect size: $0.31 ; P=0.001)$ at six months [Table 2].

Furthermore, there was a significant increase in dialysis adherence scores at six months in the experimental group compared to the control group (+0.94 versus -0.06 ; effect size: $0.51 ; P=0.001$ ). There was also a significant increase in fluid adherence scores $(+16.34$ versus +1.21 ; effect size: $2.30 ; P=0.001)$. At six months, the experimental group's diet adherence scores improved significantly compared to the control group (+61.19 versus +2.17; effect size: $4.75 ; P=0.001$ ). Finally, the increase in drug adherence scores at six months was significantly higher in the experimental group than the control group $(+10.73$ versus +2.38 ; effect size: $1.3 ; P=0.001)$ [Figure 2]. 


\section{Discussion}

The current study provides evidence that CBT resulted in a considerable increase in overall patient adherence to treatment compared to a control group receiving non-directive counselling, with significant improvements noted in terms of IDWG, systolic blood pressure, diastolic blood pressure, haemoglobin, dialysis adherence, fluid adherence, diet adherence and drug adherence. In particular, these improvements were sustained at both three and six months following the intervention. Thus, the present study's findings support those of earlier research indicating that cognitive and behavioural techniques have a significant impact on compliance to recommended diet, fluids, drugs and dialysis. ${ }^{14,24}$

In another randomised controlled trial, Sharp et al. found that CBT resulted in a reduction in mean IDWG among 56 patients receiving haemodialysis, with a significant difference between initial and follow-up weight values over a long-term assessment $(P<0.001)$, a finding indicative of improved adherence over time. ${ }^{17}$ Cukor et al. similarly affirmed that 65 haemodialysis patients receiving $\mathrm{CBT}$ experienced more significant improvements in IDWG compared to a wait-list control group $(P=0.002) .{ }^{25}$ In contrast, Nozaki et al. observed a reduction in daily weight gain compared to baseline measurements among both haemodialysis patients receiving nurse-delivered CBT patient education and those receiving structured patient education; however, the CBT group demonstrated longer maintenance of weight gain improvements (12 weeks versus eight weeks). ${ }^{26}$ In the current study, it was anecdotally observed that participants were able to make dietary choices with a greater degree of confidence after attending the CBT sessions; this form of therapy helped them to feel responsible for their adherence behaviours, whereas before they felt hopeless and less attentive to their treatment as a whole.

With regards to fluid adherence, Sagawa et al. reported that CBT resulted in a high rate (65\%) of optimal liquid consumption during the intervention phase among 10 Japanese patients on chronic haemodialysis, with patients achieving their fluid intake goal approximately $75 \%$ of the time without the need for personalised reinforcement of the behaviour. ${ }^{27}$ In turn, Anson et al. described a patient with a history of fluid overload and non-adherence who was able to reduce his daily fluid intake from $2.7-4.4 \mathrm{~L}$ to $<1.8 \mathrm{~L}$ after undergoing CBT. ${ }^{28}$ The researchers also noted a decline in both relapse frequency and the total amount of liquid consumed throughout therapy. ${ }^{28}$ Hare et al. reported a significant longitudinal difference in oedematous status among 15 patients on peritoneal dialysis with a history of non-adherence to fluid restrictions who underwent an intervention involving educational, cognitive and behavioural components, a finding which was considered indicative of improvements in adherence to fluid self-management

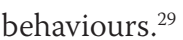

On par with the present study's findings, Moattari et al. identified a significant difference in systolic blood pressure, diastolic blood pressure, IDWG and haemoglobin and haematocrit levels in the experimental group following an empowerment programme with comparable cognitive and behavioural components. ${ }^{30}$ In contrast, Barnett et al. found that pre-dialysis mean blood pressure did not improve significantly following a patient education programme among 26 non-compliant patients with end-stage renal disease. ${ }^{31}$ Yurtkuran et al. found that a 12-week yogabased exercise programme improved erythrocyte and haematocrit counts by $11 \%$ and $13 \%$, respectively, among 37 haemodialysis patients. ${ }^{32}$ CBT intervention in the present study also had an activity component in the fifth session in which the participants were encouraged to rate the present level of activity from 1 to 10 and they were reinforced to gradually increase the level of overall activity including any form of exercise of their choice. The present study obtained a large effect size on fluid, diet and drug adherence, a medium effect size on IDWG, blood pressure and dialysis adherence and a small effect size on haemoglobin. Likely, the marked reduction in fluid consumption and improvements in diet and drug adherence contributed to the changes in other adherence indicators such as IDWG, blood pressure and haemoglobin. However, participants with low levels of haemoglobin at baseline may have had ongoing blood loss due to poor adherence to erythropoietin based on the high cost of this type of treatment.

Unfortunately, it was not possible to include other laboratory parameters which might be better indicators for drug and dietary adherence, such as serum phosphate and serum albumin, due to lack of consent for these tests from the participants. As the tests were paid for by the patients themselves, only essential laboratory investigations could be ordered by the treatment team. Moreover, the treatment team was careful to avoid adding to the patients' financial burden, particularly as many individuals had lost their jobs as a result of their disease. In addition, many participants claimed that they wanted to avoid any 'unnecessary' blood loss, which they believed would ensue from such testing.

The current study was subject to certain limitations. It is possible that participants in the experimental and control groups may have communicated details of the chosen intervention with each other. Moreover, the 
results may have been affected by measurement bias. However, it was observed that most exchanges of information between participants in different groups focused primarily on day-to-day symptoms and diseaserelated issues rather than adherence. Furthermore, most patients arrived at the haemodialysis unit at their exact appointment times which were staggered over different shifts so that they had less opportunity to interact with each other. Finally, data were collected using three different methods-reviews of the patient records, laboratory testing and personal interviews with the patients and caregivers-in order to avoid potential contamination of the data and measurement bias.

\section{Conclusion}

When used as an adjunct therapy for patients undergoing maintenance haemodialysis, CBT improves dialysis, fluid, diet and drug adherence and is beneficial for regulating physiological indicators of therapeutic adherence such as IDWG, blood pressure and haemoglobin. In light of these findings, CBT is recommended among CKD patients to improve therapeutic adherence in this population.

\section{CONFLICT OF INTEREST}

The authors declare no conflicts of interest.

\section{FUNDING}

No funding was received for this study.

\section{References}

1. Hill NR, Fatoba ST, Oke JL, Hirst JA, O'Callaghan CA, Lasserson DS, et al. Global prevalence of chronic kidney disease: A systematic review and meta-analysis. PLoS One 2016; 11:e0158765. https://doi.org/10.1371/journal.pone.0158765.

2. Wang H, Naghavi M, Allen C, Barber RM, Bhutta ZA, Carter A, et al. Global, regional, and national life expectancy, all-cause mortality, and cause-specific mortality for 249 causes of death, 1980-2015: A systematic analysis for the Global Burden of Disease Study 2015. Lancet 2016; 388:1459-544. https://doi. org/10.1016/S0140-6736(16)31012-1.

3. Centers for Disease Control and Prevention. National chronic kidney disease fact sheet, 2017. From: www.cdc.gov/diabetes/ pubs/pdf/kidney_factsheet.pdf Accessed: Jun 2020.

4. Shin SJ, Lee JH. Hemodialysis as a life-sustaining treatment at the end of life. Kidney Res Clin Pract 2018; 37:112-18. https:// doi.org/10.23876/j.krcp.2018.37.2.112

5. Valsaraj BP, Bhat SM, Prabhu R, Dinesh N. A qualitative research on the experience of haemodialysis in South Karnataka: Lived experience of persons undergoing haemodialysis. J Krishna Inst Med Sci Univ 2014; 3:90-100. https://doi.org/10.9790/195903123135 .
6. Peterson RA, Kimmel PL, Sacks CR, Mesquita ML, Simmens SJ, Reiss D. Depression, perception of illness and mortality in patients with end-stage renal disease. Int J Psychiatry Med 1991; 21:343-54. https://doi.org/10.2190/D7VA-FWEU-JN5Y-TD3E.

7. McDade-Montez EA, Christensen AJ, Cvengros JA, Lawton WJ. The role of depression symptoms in dialysis withdrawal. Health Psychol 2006; 25:198-204. https://doi.org/10.1037/02786133.25.2.198.

8. Thomas B, Wulf B, Bikbov B, Perico N, Cortinovis M, de Vaccaro KC, et al. Maintenance dialysis throughout the world in years 1990 and 2010. J Am Soc Nephrol 2015; 26:2621-33. https://doi.org/10.1681/ASN.2014101017.

9. Nesse RM. Is depression an adaptation? Arch Gen Psychiatry 2000; 57:14-20. https://doi.org/10.1001/archpsyc.57.1.14.

10. Lysaght MJ. Maintenance dialysis population dynamics: Current trends and long-term implications. J Am Soc Nephrol 2002; 13:S37-40.

11. Morgan L. A decade review: Methods to improve adherence to the treatment regimen among hemodialysis patients. Nephrol Nur J 2000; 27:299-304. https://doi.org/10.1111/j.17 55-6686.2001.tb00127.x.

12. Denhaerynck K, Manhaeve D, Dobbels F, Garzoni D, Nolte C, De Geest S. Prevalence and consequences of non-adherence to hemodialysis regimens. Am J Crit Care 2007; 16:222-35. https://doi.org/10.1097/jnr.0000000000000309.

13. World Health Organization. Adherence to long-term therapies: Policy for action - Meeting report, 4-5 June 2001. From: https:// apps.who.int/iris/handle/10665/66984 Accessed: Jun 2020.

14. Kaveh K, Kimmel PL. Compliance in hemodialysis patients: Multidimensional measures in search of a gold standard. Am J Kidney Dis 2001; 37:244-66. https://doi.org/10.1053/ajkd.20 01.21286 .

15. Beck, AT. Advances in cognitive theory and therapy. Annu Rev Clin Psychol 2014; 10:1-24. https://doi.org/10.1146/annurevclinpsy-032813-153734.

16. Matteson ML, Russell C. Interventions to improve hemodialysis adherence: A systematic review of randomised-controlled trials. Hemodial Int 2010; 14:370-82. https://doi.org/10.1111/j.15424758.2010.00462.x.

17. Sharp J, Wild MR, Gumley AI, Deighan CJ. A cognitive behavioral group approach to enhance adherence to hemodialysis fluid restrictions: A randomised controlled trial. Am J Kidney Dis 2005; 45:1046-57. https://doi.org/10.1053/j.ajkd.2005.02.032.

18. Duarte PS, Miyazaki MC, Blay SL, Sesso R. Cognitive-behavioral group therapy is an effective treatment for major depression in hemodialysis patients. Kidney Int 2009; 76:414-21. https://doi. org/10.1038/ki.2009.156.

19. Cukor D. Use of CBT to treat depression among patients on hemodialysis. Psychiatr Serv 2007; 58:711-12. https://doi. org/10.1176/appi.ps.58.5.711.

20. Valsaraj BP, Bhat SM, Latha KS. Cognitive behaviour therapy for anxiety and depression among people undergoing haemodialysis: A randomised control trial. J Clin Diagn Res 2016; 10:VC06-10. https://doi.org/10.7860/JCDR/2016/18959.8383.

21. Schulz KF, Altman DG, Moher D. CONSORT 2010 statement: Updated guidelines for reporting parallel group randomised trials. J Pharmacol Pharmacother 2010; 1:100-7. https://doi. org/10.4103/0976-500X.72352.

22. Friedman LM, Furberg CD, DeMets DL. Fundamentals of Clinical Trials, 3rd ed. New York, USA: Springer, 1998.

23. Valsaraj BP, Valsaraj P, Bhat SM, Prabhu R, George A. Development of dietary guidelines for persons undergoing hemodialysis. IOSR J Nurs Health Sci 2014; 3:31-5. https://doi. org/10.9790/1959-03123135. 
24. Welch JL, Thomas-Hawkins C. Psycho-educational strategies to promote fluid adherence in adult hemodialysis patients: A review of intervention studies. Int J Nurs Stud 2005; 42:597-608. https://doi.org/10.1016/j.ijnurstu.2004.09.015.

25. Cukor D, Ver Halen N, Asher DR, Coplan JD, Weedon J, Wyka KE, et al. Psychosocial intervention improves depression, quality of life, and fluid adherence in hemodialysis. J Am Soc Nephrol 2014; 25:196-206. https://doi.org/10.1681/ASN.2012111134.

26. Nozaki C, Oka M, Chaboyer W. The effects of a cognitive behavioural therapy programme for self-care on haemodialysis patients. Int J Nurs Pract 2005; 11:228-36. https://doi.org/10.1111/ j.1440-172X.2005.00525.x.

27. Sagawa M, Oka M, Chaboyer W. The utility of cognitive, therapy on chronic haemodialysis patients' fluid intake: A preliminary examination. Int J Nurs Stud 2003; 40:367-73. https://doi.org/10.1016/S0020-7489(02)00100-1.

28. Anson HM, Byrd MR, Koch EI. Cognitive behavioral treatment to improve adherence to haemodialysis fluid restrictions: A case report. Case Rep Med 2009; 2009:835262. https://doi. org/10.1155/2009/835262.
29. Hare J, Clark-Carter D, Forshaw M. A randomised controlled trial to evaluate the effectiveness of a cognitive behavioural group approach to improve patient adherence to peritoneal dialysis fluid restrictions: A pilot study. Nephrol Dial Transplant 2014; 29:555-64. https://doi.org/10.1093/ndt/gft477.

30. Moattari M, Ebrahimi M, Sharifi M, Rouzbeh J. The effect of empowerment on the self-efficacy, quality of life, and clinical and laboratory indicators of patients treated with hemodialysis: A randomised controlled trial. Health Qual Life Outcomes 2012; 10:115. https://doi.org/10.1186/1477-7525-10-115.

31. Barnett T, Yoong TL, Pinikahana J, Si-Yen T. Fluid compliance among patients having haemodialysis: Can an educational programme make a difference? J Adv Nurs 2008; 61:300-6. https://doi.org/10.1111/j.1365-2648.2007.04528.x.

32. Yurtkuran M, Alp A, Yurtkuran M, Dilek K. A modified yogabased exercise program in hemodialysis patients: A randomised controlled study. Complement Ther Med 2007; 15:164-71. https://doi.org/10.1016/j.ctim.2006.06.008. 